PLEASE NOTE! THIS IS PARALLEL PUBLISHED VERSION OF THE ORIGINAL ARTICLE (final draft).

To cite this Article: A. Guilland (2016) DEVELOPMENT OF ASSESSMENT OF TRANSVERSAL SKILLS IN EUROPEAN COLLABORATION. DIFFERENCES IN TEACHING AND LEARNING ENVIRONMENTS, INTED2016 Proceedings, pp. 5436-5443.

DOI: 10.21125/ inted. 2016. 0299 


\title{
DEVELOPMENT OF ASSESSMENT OF TRANSVERSAL SKILLS IN EUROPEAN COLLABORATION. DIFFERENCES IN TEACHING AND LEARNING ENVIRONMENTS
}

\author{
A. Guilland \\ Laurea University of Applied Sciences (FINLAND)
}

\begin{abstract}
The development of digital technology and logistics has promoted globalisation and modernisation of working life creating an increasingly interconnected world. Individuals need to master various technologies and to continuously select between and make sense of large amounts of information. Modern societies also face collective challenges such as balancing economic growth with environmental sustainability, and prosperity with social equity. In these contexts, the competences that individuals need to display, have become more complex, requiring more than mastering of certain limited skills.

Educational authorities issue guidelines on what should be taught or learnt in schools. Usually these guidelines are included as part of curriculum documents or syllabuses. In recent years, reforms in many countries have reshaped curricula on the basis of new concepts such as 'key competences' and 'learning outcomes' and some have introduced achievement scales. In numerous countries, a subjectbased organisation with a focus on subject content has given way to a more complex curricular architecture built, in part, on practical skills and on cross-curricular approaches.
\end{abstract}

New interactive learning environments have been developed to facilitate active learning. These learning environments, promote collaborative and multidisciplinary learning and are increasingly technology enhanced. They allow several transversal competences to be addressed simultaneously. However, these modern pedagogical approaches have not been adopted everywhere.

Relatively little importance has been given to cross-border collaboration in developing education. This paper discusses ongoing cross-border collaboration between six European higher educational institutes. Focus of the discussion is on differences in teaching and learning practices in the institutes. Some development obstacles are identified and their influence on cross-border collaboration are reflected.

Keywords: Competences, transversal skills, learning environments, research and development, intercultural collaboration.

\section{INTRODUCTION}

Huge technological changes have considerably modified our world during the last centuries. Development of digital technology and logistics have promoted rapid globalisation and modernisation of human life creating an increasingly diverse and interconnected world. This has influenced both humans, organisations, society and nature. Today modern societies face collective challenges such as balancing economic growth with environmental sustainability, and prosperity with social equity. At the same time, the world is becoming increasingly difficult to predict and manage. This is important to take into consideration when preparing for future working life [1].

\subsection{Challenges of future working life}

We know little of the future working life although various studies concentrate on building pictures of it. The technological revolution is continuous and much of the technology that will be used in future is not yet available. Moreover, adoption of technology requires time. Each euro used for development of technology, requires a tenfold investment in assurance of transition of human thinking patterns as well as human and organisational practices [2]. In working life, control, compliance, and compartmentalisation (3 C's) are being outplaced by ideas, information, and interaction (3 I's) [3]. 
Even though important advances are made in technology, humans hold important roles. No technology allows the artificial brain to replace humans in the capacity of thinking independently. Humans will be needed in business, management, innovation and development, marketing and sales. Photographers, musicians, painters and designers will be needed. [2]

In communication between humans the role of gestures, body language, way of talking and the person's private history play an important role. In this respect humans will remain superior to machines even in the future and jobs where facing people is crucial like in medicine and nursing, safe jobs will remain available. Moreover, humans are needed in motivating others, which leaves working possibilities e.g. for teachers, educators, therapists. [2]

Even though robots become increasingly performant, they cannot completely replace human senses and motorics in fields such as medicine and nursing. Rise of technicality of the society creates continuously new needs and new working opportunities. Humans remain behind all technical development and people are needed for innovating use for the new technology and then developing the technical solutions. At the same time people are needed in production, marketing, use, maintenance, recycling. Software architects, database designers and ICT-experts will be among the most secured jobs in the future. [2]

Also the situations related to professional engagements are changing. Having a job does not mean holding the same role in the organization for ever. The recent financial crisis has shown that people have to adapt their role to the requirements of the organization. New tasks can be given at the same time as part of the previous ones may lose their importance. Many tasks disappear, will be taken care of by machines or will be outsourced. Taking over new tasks means facing new challenges, learning new skills, using new information, adapting to new working conditions and so on. As job markets change, individuals might have to change their working profile and learn a completely new profession. This can be based on the person's own initiative, as is often the case when the working conditions deteriorate considerably, as is the case among nurses in various European countries [4] or losing the job. Many also wish to try a new profession, advance their career and experience new occupational challenges [5].

\subsection{Renewal of educational goals}

Future working life, social cohesion as well as active citizenship, require good generic competences. Several international organisations have developed frameworks for distinguishing these competences. A European recommendation lists eight Key Competences for Life Long Learning: communication in mother tongue; communication in a foreign language; mediation and intercultural understanding; mathematical competences and basic competences in science and technology; digital competences; learning to learn; social and civic competences; sense of initiative and entrepreneurship; cultural awareness and expression [6]. Moreover, so called Transversal or Soft Skills, namely critical thinking, creativity, initiative, problem solving, risk assessment, decision making, communication and constructive management of feelings, are relevant across all the Key Competences. [7]

The European Commission has communicated clear priorities for education and training concerning the key competences. However, in many countries the educational goals are still under development and in practice these competences are taught using different methods. Related subjects may have cross-curricular status, they may be integrated into existing curriculum subjects or they may be introduced separately. Learning goals of these competences are often lacking and in each case different assessment is used. [7]

\subsection{Rethinking teaching and assessment}

The "pedagogical core" of learning environments consists of learners, educators, content and resources. Innovation of any learning environment requires rethinking the elements of the pedagogical core. The organisation and pedagogy (incl. individual vs group work; flexibility and personalisation of use of time; use of various assessment methods) link the elements of the pedagogical core together. Learners can consist of face-to-face and distant (online) participants. Educators can be teachers from the own or outside organisation or other partners including advisors or experts from public, private or third sector organisations. [8] As the council and the representatives of the governments of the European member states concluded, "Education and training institutions at all levels - from schools through to vocational, adult and higher education institutions - should, to the appropriate extent, seek greater openness and responsiveness to the wider world and actively communicate with other partners in society at large" [9]. 
Future challenges require rethinking of teaching and learning approaches. This can include a transition from teacher to learner centred approach; shift responsibility for learning to the learner; offer team learning opportunities aside to individual work; replace pure memorizing by learning to find, critically evaluate, select and apply information.

Learning experience is more likely to have significant, positive gains for the learners if they are active rather than passive recipients within it. Learning in a passive system has a much greater tendency to be both superficial and quickly forgotten. [10]

Modern learning environments are interactive and offer development of communication. Multidisciplinary disciplinary and technology enhanced environments enable learning and expression of various competences. Modern teaching and assessment methods based both on individual and team approaches can encourage the learners to take over of an active role in learning their learning process. Working in collaboration with industry for developing solutions for their real challenges enables teaching and learning in working life, through real working life challenges and for working life [11].

Assessment can at its best be seen as an integral part and an on-going parallel process to teaching and learning. With the help of a mixed set of assessment methods, including self- and peerassessment, the learners have the possibility of following their own learning process and progress as well as reflect it in relation to their individual learning goals and available resources [12]. Welldesigned assessment tasks, where students work together and actively learn and practice self- and peer-assessment, engage students in the assessment process [13].

\section{STUDY}

This study was part of a European project called SOCCES - SOCial Competences, Entrepreneurship and Sense of Initiative - Development and Assessment Framework. The project was funded (20152017) by the Erasmus + program and is part of the Erasmus+ "Key action Cooperation for innovation and the exchange of good practices" in the field of "Strategic Partnerships for higher education". The aim of SOCCES was to develop and pilot a framework for the methodical assessment of these working life competences.

\subsection{Goals}

The baseline study concentrated on existing teacher practices, mapping of the current educational environments and practices and defining the main development needs regarding the assessment framework and the defined competences and the related skills.

The goal of this study was to collect information and create understanding of the teaching and learning practices in higher education institutes (HEI) in the participating organisations enabling development and piloting of an assessment method and related learning assignment.

The research questions were: 1) What teaching and learning practices are common in the organisations? 2) Do the organisations include industry collaboration in teaching and learning? 3) What role does virtual learning play in teaching and learning? 4) What are the possible and/or most important stumbling blocks concerning the use of a joint learning approach and assessment method in these different educational environments?

The main limitation of the study was that it consisted only one HEl per country and concentrated mainly on one faculty in each organisation. This was sufficient for the purpose of the project. However the sample is not representative of HEl in Europe nor even in each country. It limits to giving examples and showing differences in teaching and learning approaches and practices.

\subsection{Materials and methods}

For collecting rich data a qualitative approach was chosen. Six partner higher education institutes from Southern, Northern, Eastern and Western Europe participated in the study. Each organisation included in the study ten informants. 
A questionnaire with open ended questions was created encouraging the informants to give as much insight as possible on the on their teaching and learning practices. Probing was used for triggering informants to prepare their answer. The main probe consisted of an example of company collaboration in the context of a partner HEI. After testing, the final questionnaires were sent by email.

A qualitative data-driven analysis was realised by collating first the responses. Then the data were coded and codes were organised into themes and subthemes and a thematic map developed. Finally appropriate examples of each theme were selected to describe and visualise the results. The analysis was executed by experienced researchers who are familiar with various modern teaching and learning approaches.

\subsection{Findings}

The study revealed important differences in teaching and learning practices in the partner organisations. Several themes were highlighted. These concern learners, educators, content and resources. These main themes are in line with the pedagogical core presented in the OECD report [8]. The following three diagrams (Diag.) present the main themes revealed by the study with related examples.

Diag. 1: Teacher and learner and on the other hand theory and practice in the pedagogical approaches practices of the studied $\mathrm{HEI}$.

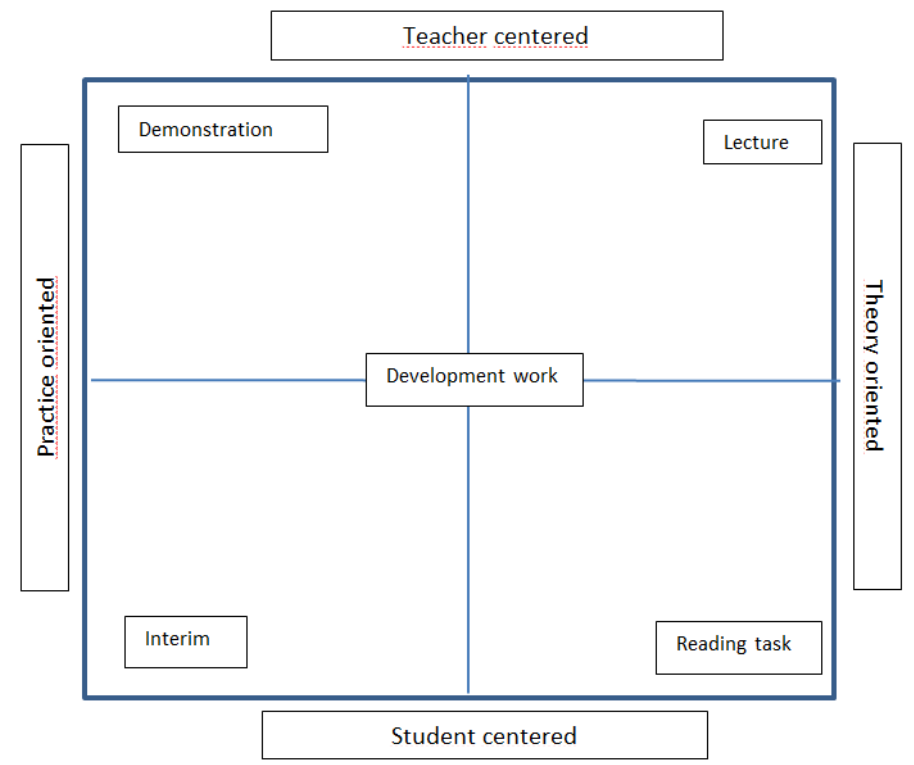

Diag. 1 presents two main themes that revealed differences in the studied HEI. On the one hand, the role of the teacher and student, and on the other hand, the typical contents and practices of teaching and learning. The diagram is divided in four blocks in relation to the role the teacher and student had and on the typical contents and practices. The block in the upper left corner gives demonstrations as an example of theory oriented, teacher centred teaching. The lower left corner mentions interim as an example of a practice oriented, student centred approach. On the right hand both the lower and higher block are related to theory oriented teaching and learning. Here the upper right block mentions lectures as a typical example of a teacher centred approach and the lower block reading task as examples of student centred, theory oriented approach. In the centre, as an example of a balanced mix of the two themes is a development work where teachers and students learn together combining theory and practice.

Diag. 2: Examples of individual and collaborative assignments related to teaching and learning practice vs theory to individuals vs. teams. 


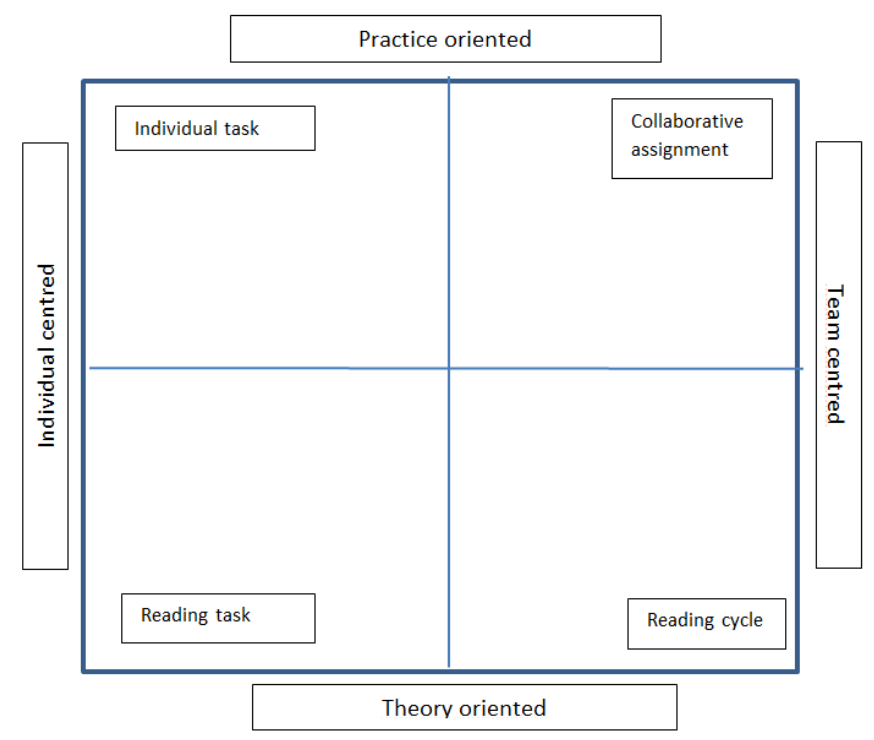

Diag. 2 is divided into four blocks in relation to typical assignments given to students in the participating HEl: theory vs practice and individual vs team assignments. An individual task is mentioned as a typical practice oriented learning assignment given to individuals whereas in the lower left block a reading task describes an individual theory oriented assignment. On the right a collaborative assignment is an example of a practice oriented, and a reading cycle as a theory oriented team centred assignment.

Diag. 3: Three different main themes related to teaching and learning in the studied HEI.

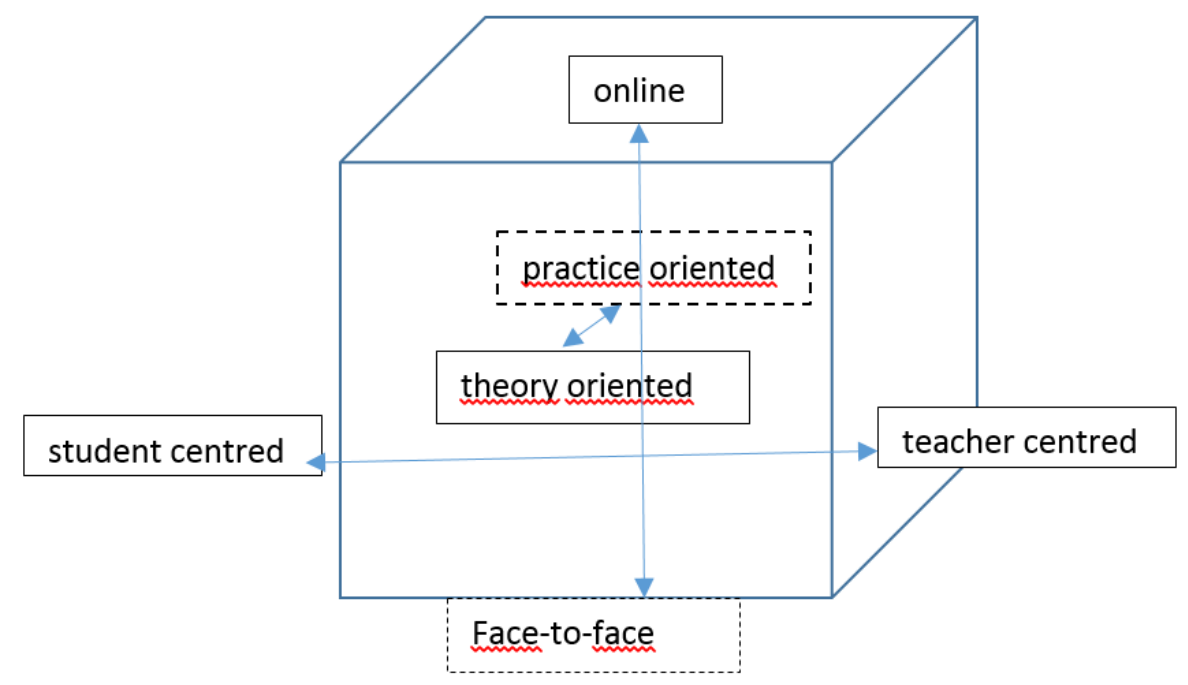

Diag. 3 is a collation of the two previous diagrams bringing along also a third main theme: the role of ICT in teaching and learning. The left and right sides of the cube reflect the roles and responsibilities. Either the student holds a key role in learning taking the initiative of searching information and critically evaluating it or the teacher has this and other teaching and learning related responsibilities. The front and back side of the cube present the type of the contents in teaching and learning (theory vs. practice oriented). The top and bottom present the teaching approach: either face-to-face or online. Inside the cube are the various intermediate form that go between the extremes. One key element is still missing, the type of learning assignments given to students, whether collaborative or individual.

Diag.4 below presents graphically the previously mentioned themes in function to the main variables: student versus (vs) teacher centred teaching and learning; practice vs theory oriented teaching and learning; face-to-face vs mobile teaching and learning; individual vs team assignments. 
Diag.4. Teaching and learning practices in six studied higher education institutes in Europe.

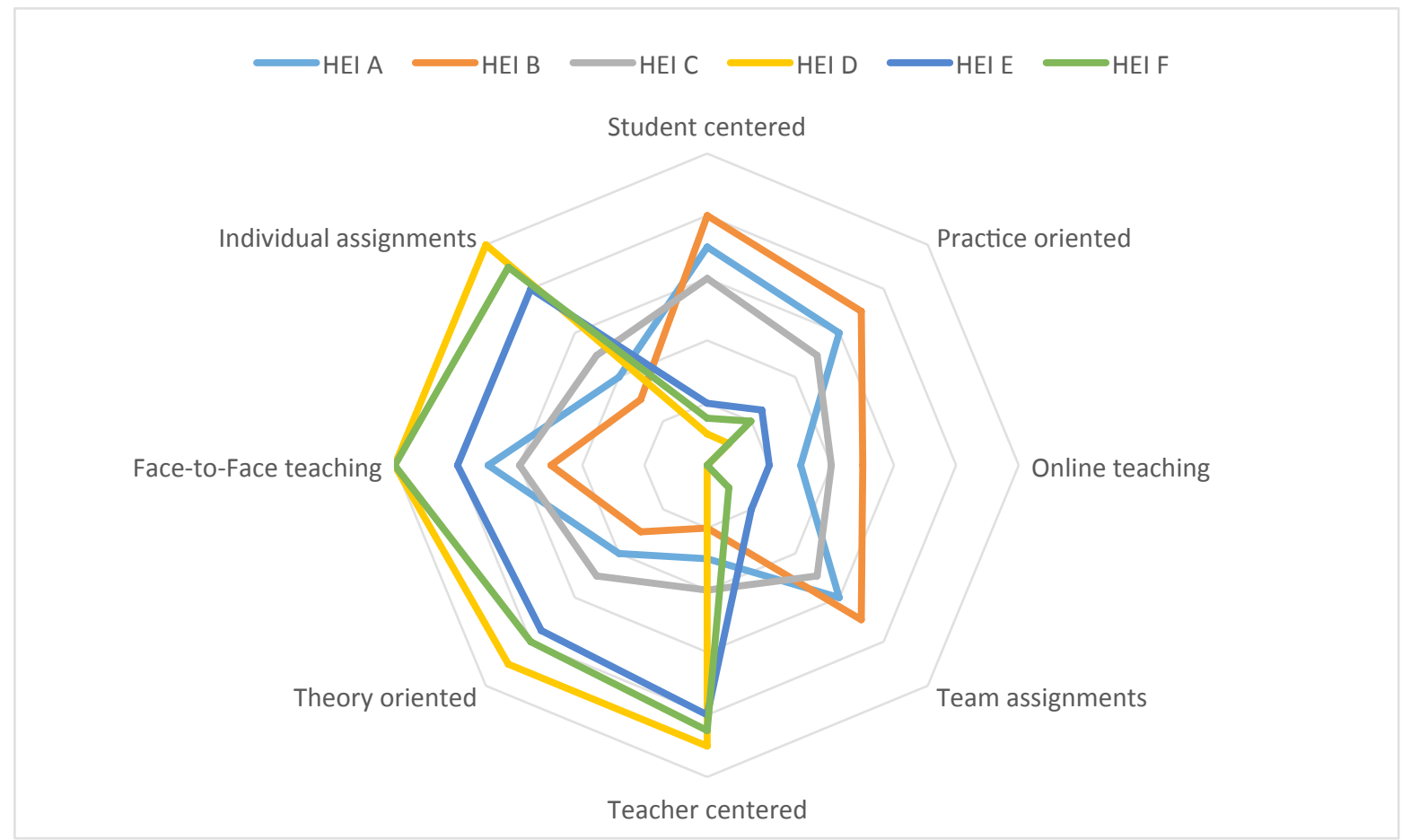

According to the results there were basically two types of organisations, and three partners fell in each type: a) those with more traditional pedagogical approaches and b) those applying different types of collaborative learning approaches [14] such as Problem based learning, Activity Led Learning (ALL) and Learning by Developing (LbD). It must however in all organisations there were appeared differences among study programmes and naturally also between individual teachers. Due partly to this, the results do not justify numeric presentation of the differences and therefore the graphics concentrates on presenting the tendencies concerning the selected factors and the main differences in these tendencies.

In all HEI teaching consisted to some extent of face-to-face (10-90\%) sessions. The nature and extent of these sessions varied. In some HEI lecturing was the main form of teaching, in some organisations lecturing held only a minor role. Individual tasks were given in all organisations whereas collaborative work was part of the teaching and learning process in only part of the organisations.

Teachers and learners roles varied accordingly: in organisations concentrating mainly on lecturing and teachers mainly provided the information. In these HEI students might not be used to looking for information and critically evaluating it in regards to the use. In other $\mathrm{HEl}$, teachers and learners shared the role and responsibility for assuring the knowledge basis. These organisations also seemed to be more open to outside experts as well as to interdisciplinary collaboration.

Some of the organisations were more practice and others theory oriented. However, there was no reason to think that any of the participating organisations would have a purely theoretical approach in teaching.

Company collaboration existed at some level in all studied organisations. The frequency and the intensity of collaboration varied. In part of the organisations real life challenges were in the centre of teaching and learning. In some, collaboration consisted of occasional guest lectures. In most $\mathrm{HEI}$ and faculties the offered study programmes consisted of at least one interim period.

As stated by the Council of the European Union (2009), "competitiveness and growth of Europe's economy could be improved by putting the knowledge triangle to work, notably by developing partnerships between employers and education and research institutions which are aimed at fostering innovation and ensuring its transfer into practice" [9]. 
In most of the organisations ICT and virtual learning environments were in an elementary role in teaching and learning. In two cases they were not a part of normal teaching practices. In one HEI with a very refined eLearning platform, the use was limited to special eLearning programmes.

In a thoughtful mix of face-to-face and online learning experiences, face-to-face oral communication is blended with online written communication, simulations, tutorials and assessment according to the intended educational purpose. This, so called blended learning, supports learning experiences outside the classroom and enables also cross-border activities [15] [16]. Rajamäki and Pirinen (2008) claimed that this approach brings "added value for learning assisted by multimedia, artificial intelligence and/or virtual reality and time saving proffered by network technologies" [16].

As for assessment, the practices varied between traditional "closed book" exams, which are practices do some extent in all $\mathrm{HEI}$. Also assessment practices existed in part of the organised. Open book exams, evaluation of team results presented in the form of reports and/or presentations, as well as self- and peer-assessment were examples of other assessment forms.

\section{DISCUSSION AND SUMMARY}

This baseline study was a part of a research and development project aiming at developing a common assessment framework for assessing transversal skills. The final product of the project is an assessment method and related learning assignment based on a business case.

The aim was to collect information on the existing teaching and learning practices and create awareness of the possible stumbling blocks so that they could be avoided. The assessment practices were in the focus of another parallel study, which has been presented by Terzieva et al, (2015).

The study revealed important differences in teaching in learning practices among the studied HEI. This can be related to cultural tradition, history as well as organisational issues. These differences lead to several stumbling blocks requiring modifications in the initial research and development project plan.

The most important finding is, that a common, collaborative working life centred learning task does not suit the teaching and learning practices in all partner organisations. One out of two organisations do not integrate such assignments in teaching. Students are not on equal footing in selecting information, using various development methods, working in teams nor working on a virtual platform.

The results on testing the assessment method will evidently depend on the choice of students in the recruitment process. Students who are used to modern learning environments might have better results than the ones following a more traditional pedagogical approach. Modern teaching and learning environments include multiple assessment methods such as self- and peer-assessment.

This study raised the question on how partners should best be selected for an intercultural project and what should be know about the partners in advance for assuring a valid plan for the research and development work. It is common practice to build a project consortium on the basis of the strengths and possible complementary role of each partner. For assuring vast long term use of the final results of a project, it might be useful to put more emphasis on the differences between partners and the eventual stumbling stones.

Collaboration at all level definitely give rise to questioning existing attitudes, values and practices. This is certainly the asset that justifies consortiums consisting of very different kind of players. In some cases, the differences may however prove to be hindrances that should be seriously reflected and critically analysed to assure best outcome of the project and value for money in the sense of large exploitation of the results.

\section{REFERENCES}

[1] Schleicher, A. (2015). Redesigning Education for the Transforming World. In: Four-Dimensional Education. The Competencies Learners Need to Succeed. Boston, MA: The Center for Curriculum Redesign, p. 13.

[2] Rouvinen, P. \& Pajarinen, M. (2014). Uudet teknologiat ja Työ. Taustamuistio TEMin Työn tulevaisuus -seminaariin 5.5.2014 Finlandia-talolla, Helsinki, Finland: Ministry of Employment and Economy (TEM).

[3] Ketz de Vries, M. (2006). The leadership mystique. Leading behavior in the human enterprise. 2nd edition. UK: Pearson Education Limited. 
[4] Heinen, M., van Achterberg, T., Schwendimann, R., Zander, B., A Matthews, A., M Kózka, M., Ensio, A. et al. (2013). Nurses' intention to leave their profession: A cross sectional observational study in 10 European countries. International Journal of Nursing Studies 50(2), pp. 174-184.

[5] Tuppurainen, S. (2010). Nuorten asenteita työtä, työn sisältöä ja koulutusta kohtaan. Työpolittinen Aikakausikirja 4, pp. 14-22.

[6] European Parliament and Council. (2006). Recommendation. Key competences for lifelong learning. 2006/962/EC. Official Journal L 394.

[7] Terzieva, L., Luppi, E. \& Traina, I. (2015). Teaching and Assessing Transferrable/Transversal Competences. Science \& Research 8, pp. 25-56.

[8] OECD. (2013). Innovative Learning Environments, Educational Research and Innovation. OECD Publishing. DOI: 10.1787/9789264203488-en

[9] Council of the European Union. (2009). Outcome of Proceedings. Conclusions of the Council and the Representatives of the Governments of the Member States, meeting within the Council, of 12 May 2009 on enhancing partnerships between education and training institutions and social partners, in particular employers, in the context of lifelong learning. Brussels, 9876/09 EDUC 90 SOC 329 COMPET 273.

[10] Wilson-Medhurst, S. (2008). Towards Sustainable Activity Led Learning Innovations in Teaching, Learning and Assessment. Loughborough University, UK: Proceedings of the International Conference on Innovation, Good Practice and Research in Engineering Education EE2008.

[11] Raij, K. (2007). Learning by Developing. Laurea Publications A-58. Laurea University of Applied Sciences. Vantaa: Edita Oy.

[12] Thomas, G., Martin, D. \& Pleasants, K. (2011). Using self- and peer-assessment to enhance students' future-learning in higher education. Journal of University Teaching \& Learning 8 (1).

[13] Kearney, S. (2013). Improving engagement: the use of 'Authentic self-and peer-assessment for learning' to enhance the student learning experience. Assessment \& Evaluation in Higher Education 38 (1), pp. 875-891.

[14] Soetanto, R., Childs, M., Poh, P., Austin, S. \& Hao, J. (2014). Virtual collaborative learning for building design. Proceedings of the Institution of Civil Engineers. Management, Procurement and Law 167 (1), pp. 25-34.

[15] Garrison, D. \& Vaughan, N. (2008). Blended Learning in Higher Education: Framework, Principles, and Guidelines. San Francisco, California: Jossey \& Bass.

[16] Pirinen, R. \& Rajamäki, J. (2008). Further derivative dimensions of learning can be identified namely individual's learning; community's learning and building new know-how. WSEAS Transactions on Advance in Engineering Education 9 (7), pp. 624-634. 